\title{
Presentación del volumen 11/3 (2020)
}

\author{
Marita Giménez-Candela \\ Catedrática \\ Directora del ICALP y del Máster en Derecho Animal (UAB) \\ ORCID: 0000-002-0755-5928
}

Recepción: Octubre 2020

Aceptación: Octubre 2020

Cita recomendada. GIMENEZ-CANDELA, M., Presentación del volumen 11/3 (2020), dA. Derecho Animal (Forum of Animal Law Studies) 11/3 (2020). - DOI https://doi.org/10.5565/rev/da.541

\section{Resumen}

El volumen 11/3 (2020) culmina el trabajo ordinario de la revista a lo largo de unos meses presididos por la incertidumbre de la pandemia. Coherentes con el compromiso de llegar a muchos lectores, ofrecemos una selección de autores y de temas de alta calidad y permanente interés.

Palabras clave: 2020; editorial; tauromaquia; transporte de animales; Código penal

El vol. 11/3 (2020) se inicia con tres artículos de investigación sobre dos creaciones humanas en las que los animales derraman sangre sin ninguna justificación ni utilidad: la tauromaquia y la guerra.

Publicamos, por primera vez, un artículo de investigación sobre un tema poco investigado: el tratamiento jurídico de los animales involucrados en conflictos armados. ${ }^{1}$ En efecto, el Derecho Internacional Humanitario, que es el conjunto de normas aplicables a los conflictos armados y a la protección de las víctimas de estos conflictos, sigue olvidando que los animales sufren y se mueren en eventos que ciertamente ellos no han provocado. En el artículo "Guerra trans-especie: Animales en conflicto humano" el profesor Joaquín David Rodríguez Álvarez (Universitat Autònoma de Barcelona) después de describir el uso y abuso de los animales en conflictos bélicos y acciones terroristas, llama la atención sobre la necesidad de adoptar normas jurídicas que prohíban el uso de animales como combatientes o armas ellos mismos. El profesor Rodríguez toca también uno de los nervios descubiertos de la cuestión: reconocer que los animales pueden ser "víctimas" de conflictos o terrorismo, pues hasta ahora sólo los humanos benefician de esta consideración. Una vez más, el Derecho tiene un largo camino por recorrer y la academia ${ }^{2}$ puede dar su contribución para que se adopten nuevas normas para proteger a los animales frente a esta forma de crueldad o que, al menos, se continúe el debate sobre este tema.

El número retoma un tema que la revista ha tratado extensamente en sus once años de actividad: el debate político, jurídico y cultural sobre la tauromaquia, en el que siempre se han confrontado los partidarios

\footnotetext{
${ }^{1}$ La literatura jurídica no es abundante. Vid. esp. NOWROT, K., Animals at war: the status of "animal soldiers" under international humanitarian law, in Historical Social Research 40/4 (2015) 128-150; HEMPTINNE, J. de, The Protection of Animals during Warfare, in AJIL, 111 (2017) 272-276, https://doi.org/10.1017/aju.2017.69

${ }^{2}$ Vid. el proyecto "Animals in the International Law of Armed Conflicts", Max Planck Institute for Comparative Public Law and International Law / University of Geneva (2018-2020): http://www.mpil.de/en/pub/research/areas/public-international-law/globalanimal-law.cfm
} 
de los espectáculos taurinos y sus opositores. ${ }^{3}$ En su artículo "La instrumentalización de los animales para el logro de objetivos políticos: el debate parlamentario sobre los toros en España”, la Profesora María José Bernuz Benéitez (Universidad de Zaragoza) explica esta contraposición mediante la reconstrucción y el análisis de los debates parlamentarios que tuvieron lugar antes la aprobación de la "Ley 18/2013 para la regulación de la Tauromaquia como patrimonio cultural", que reflejan la existencia de la cuestión de la identidad española y la ausencia de una posición univoca sobre esta realidad divisiva. Este debate a favor o contra los espectáculos no es nuevo, ya que se remonta al S. XIII y atraviesa la historia española. El doctor Juan Ignacio Codina Segovia (Observatorio Justicia y Defensa Animal) en su artículo « Legislación civil y religiosa contra la tauromaquia: prohibiciones históricas de los espectáculos taurinos en España entre 1567 y $1936 »$ nos lleva a través del tiempo y nos permite descubrir las medidas que se adoptaron para prohibir o reducir estos espectáculos de sangre. ${ }^{4}$

Desde su creación, esta revista también ha sido una ventana abierta al mundo jurídico latinoamericano, por el lenguaje común, la cultura y los lazos que los investigadores de varias universidades han tejido en torno al problema de los animales en el Derecho y otras Ciencias que lo tratan. ${ }^{5}$ En este número publicamos el comentario de la profesora Rosa María de la Torre Torres (Universidad Michoacana de San Nicolás de Hidalgo, México) cuyo título "El bienestar animal como principio constitucional implícito y como límite proporcional y justificado a los derechos fundamentales en la Constitución mexicana" se refiere a una importante resolución de la jurisprudencia mexicana en tema de interpretación del bienestar animal desde la perspectiva constitucional. Este comentario analiza de forma crítica y detallada los antecedentes de la demanda de amparo y del recurso de revisión, ofreciendo también reflexiones sobre el contexto jurídico en el que se ha llegado a esta decisión. Chile es otro país en el que se han adoptado reformas para mejorar las normas sobre el maltrato animal. En el comentario "Delito de maltrato animal en el Anteproyecto de Nuevo Código Penal de Chile de 2018”, el abogado José Ignacio Binfa Álvarez presenta la situación legislativa actual, a través de un análisis crítico y exhaustivo de fuentes y literatura. La revista publica también un interesante excursus jurídico y cultural sobre el tratamiento de los animales en otro país latinoamericano que ha desarrollado el debate, más amplio, sobre la naturaleza desde hace años: "Los derechos de los animales: una aproximación a los Derechos de la Naturaleza en el Ecuador" por el profesor Mauro Leonel Fuentes, Ms. (Universidad de Guayaqui).

La revista, también en este número, mantiene su vocación de promover las investigaciones de los Alumni del Máster en Derecho Animal Y Sociedad (UAB) que aportan ideas y propuestas sólidas para que la promoción de los intereses de los animales à través de normas jurídicas se concreticen en nuestras sociedades democráticas. ${ }^{6}$ Por eso, el papel de la prensa es esencial para relatar la vida de los animales al público, de manera imparcial y ajena de los prejuicios. Es lo que analiza, con rigor y precisión, Rebeca García Rodríguez (MA Derecho Animal y Sociedad, licenciada en Periodismo) en el documento "El poder del discurso en los medios de comunicación: análisis de prensa de la representación de los animales de granja". No se debe olvidar que los animales de granja se transportan en viajes largos, antes de llegar al destino final: el matadero. Silvia Meriggi (MA Derecho Animal y Sociedad, Investigadora en la ONG Animals' Angels) en el documento "La armonización de la protección animal durante el transporte en la Unión Europea - Análisis del sistema de sanciones en Italia, Rumanía y España" analiza como estos tres países aplican el Reglamento (CE) 1/2005 , cuál es el sistema sancionador de cada país analizado, qué se podría hacer para mejorar la armonización de la legislación de la Unión Europea. Esta investigación tiene el mérito de haberse realizado con conocimiento directo del tema tratado, pues la autora colabora con Animals' Angels, una ONG alemana que elabora informes que evidencian como las normas jurídicas se pueden enfrentar a la realidad del transporte de animales.

¿Para qué sirven las leyes si no hay respeto? De qué sirve luchar por grandes causas si se olvidan a

\footnotetext{
${ }^{3}$ Vid. por todos, GIMÉNEZ-CANDELA, M., Cultura y maltrato animal, dA. Derecho Animal (Forum of Animal Law Studies) 10/3 (2019) 7-14. DOI: https://doi.org/10.5565/rev/da.453; VERICAT TORNÉ, El patriarcado en la corrida de toros, dA. Derecho Animal (Forum of Animal Law Studies) 10/4 (2019) DOI: https://doi.org/10.5565/rev/da.447; CANO HERRERA, M., Tauromaquia e identidad moral de Cataluña, en dA. Derecho Animal (Forum of Animal Law Studies) 1/3 (2010) 1 ss. DOI: https://doi.org/10.5565/rev/da.221. Vid. también GIMÉNEZ-CANDELA, M., Transición animal en España (Valencia 2019) 29, 77$79,83,88-90,95,96,100-103,139-141,147$.

${ }^{4}$ El autor ya ha publicado un libro sobre este tema. CODINA SEGOVIA, J.I., Pan y Toros, Breve Historia del Pensamiento antitaurino español (Madrid 2018), rec. de ALÁEZ CORRAL, B., en dA. Derecho Animal (Forum of Animal Law Studies) 10/1 (2019), DOI: https://doi.org/10.5565/rev/da.391

5 Se reenvía a la consulta de los Archivos de la revista dA. Derecho Animal (Forum of Animal Law Studies): https://revistes.uab.cat/da/issue/archive

${ }^{6}$ Ibíd.

${ }^{7}$ Reglamento (CE) n ${ }^{\circ}$ 1/2005 del Consejo, de 22 de diciembre de 2004, relativo a la protección de los animales durante el transporte y las operaciones conexas y por el que se modifican las Directivas 64/432/CEE y 93/119/CE y el Reglamento (CE) $n^{\circ} 1255 / 97$, https://eur-lex.europa.eu/legal-content/ES/TXT/?uri=celex:32005R0001
}

8 Derecho Animal. Forum of Animal Law Studies, vol. 11/3 
algunos seres vulnerables? Mucho se ha dicho sobre la ética de la relación entre el hombre y el animal, pero el sufrimiento de los animales continúa y eso no es digno de los humanos. Desde esta perspectiva, hay que repetir palabras, que ya se han dicho, y añadir ideas nuevas. Y siempre cuestionar la realidad, discutir. ${ }^{8}$ Son estimulantes, en este sentido, las reflexiones del Profesor Georges Chapouthier (Director emérito del Centro Nacional de la investigación científica en Francia, neurobiólogo y filósofo). Su contribución "Respetar a los animales para poder respetar a los humanos" debería pulsar las conciencias y fomentar el respeto por los débiles y vulnerables, por parte de los más fuertes. El respeto es algo que se puede enseñar y aprender. ${ }^{9}$

El vol. 11/3 (2020) se cierra con la reseña critica de mi último libro "Transición Animal en España". Escrita por Iván Fructuoso González (letrado de la Administración de Justicia), esta reseña contiene una descripción y una valoración de esta obra que, espero, ayude dejar rastro de lo que no existía en nuestro país, de los esfuerzos realizados, de las esperanzas y decepciones, de la determinación clara de no abandonar esta necesaria lucha jurídica por los animales.

\section{Referencias}

- Archivos de la revista dA. Derecho Animal (Forum of Animal Law Studies): https://revistes.uab.cat/da/issue/archive

- CANO HERRERA, M., Tauromaquia e identidad moral de Cataluña, en dA. Derecho Animal (Forum of Animal Law Studies) 1/3 (2010) 1 ss. DOI: https://doi.org/10.5565/rev/da.221.

- CODINA SEGOVIA, J.I., Pan y Toros, Breve Historia del Pensamiento antitaurino español (Madrid 2018), rec. de ALÁEZ CORRAL, B., en dA. Derecho Animal (Forum of Animal Law Studies) 10/1 (2019), DOI: https://doi.org/10.5565/rev/da.391

- GIMÉNEZ-CANDELA, T., Educar para la convivencia. Educar para la paz, en dA. Derecho Animal (Forum of Animal Law Studies) 1/3 (2010) 1-2. https://doi.org/10.5565/rev/da.310

- GIMÉNEZ-CANDELA, M., Cultura y maltrato animal, dA. Derecho Animal (Forum of Animal Law Studies) 10/3 (2019) 7-14. DOI: https://doi.org/10.5565/rev/da.453

- GIMÉNEZ-CANDELA, M., Transición animal en España (Valencia 2019)

- HEMPTINNE, J. de, The Protection of Animals during Warfare, in AJIL, 111 (2017) 272-276, https://doi.org/10.1017/aju.2017.69

- NOWROT, K., Animals at war: the status of "animal soldiers" under international humanitarian law, in Historical Social Research 40/4 (2015) 128-150;

- POLLO, S., Umani e animali: questioni di etica (Roma 2016)

- Proyecto "Animals in the International Law of Armed Conflicts", Max Planck Institute for Comparative Public Law and International Law / University of Geneva (2018-2020): http://www.mpil.de/en/pub/research/areas/public-international-law/global-animal-law.cfm

- VERICAT TORNÉ, El patriarcado en la corrida de toros, dA. Derecho Animal (Forum of Animal Law Studies) 10/4 (2019) DOI: https://doi.org/10.5565/rev/da.447

- Reglamento (CE) n ${ }^{\circ} 1 / 2005$ del Consejo, de 22 de diciembre de 2004, relativo a la protección de los animales durante el transporte y las operaciones conexas y por el que se modifican las Directivas 64/432/CEE y 93/119/CE y el Reglamento (CE) no 1255/97, https://eur-lex.europa.eu/legalcontent/ES/TXT/?uri=celex:32005R0001

\footnotetext{
${ }^{8}$ POLLO, S., Umani e animali: questioni di etica (Roma 2016)

${ }^{9}$ En este sentido, vid. también GIMÉNEZ-CANDELA, T., Educar para la convivencia. Educar para la paz, en dA. Derecho Animal (Forum of Animal Law Studies) 1/3 (2010) 1-2. https://doi.org/10.5565/rev/da.310
} 